\title{
Characterising Resilience: Unpacking the concept for tackling climate change and development
}

\author{
Bahadur, A.V. Ibrahim, M. and Tanner, T.
}

\begin{abstract}
AAM Version. Please cite as:
Bahadur, A.V. Ibrahim, M. and Tanner, T. (2013) 'Characterising resilience: unpacking the concept for tackling climate change and development'. Climate and Development, (5) 1, pp 55-65.
\end{abstract}

\begin{abstract}
The term 'resilience' is increasingly used in the context of discussion, policies and programming around climate change adaptation ${ }^{1}$ ('adaptation') and disaster risk reduction ${ }^{2}$ (DRR). It has become particularly popular to describe the intersection between these two fields and those of poverty and development, and 'climate resilient development' is rapidly becoming a catch-all for tackling climate change impacts in a development context. This paper reviews academic use of the concept of 'resilience' in social, ecological and socioecological systems and its application to the climate, disaster and development nexus. From this review, we distil ten key characteristics of resilience: high diversity; effective governance and institutions; the ability to work with uncertainty and change; community involvement and the appropriation of local knowledge; preparedness and planning for disturbances; high social and economic equity; robust social values and structures, acknowledging non equilibrium dynamics, continual and effective learning and the adoption of a cross-scalar perspective. Finally we highlight knowledge gaps and suggest directions for further research.
\end{abstract}

Key Words: Resilience, adaptation, disaster risk reduction, climate resilient development, socio-ecological systems. 


\section{Introduction}

\subsection{The renaissance of resilience?}

Resilience is increasingly employed as a concept to guide praxis on climate change and development. There has been a marked spike in academic interest around this subject in the last decade and corresponding with this, an increasing number of organisations are attempting to integrate the tenets of 'resilience thinking' in their work (EcologicalSociology 2012). Academic resilience thinking has multiple and diverse meanings, traversing a number of disciplines and communities of practice, such as psychology, engineering, business and technology innovation, and social sciences. However, there has been little attempt to scrutinise the literature to examine the variations in its definition and use. This paper is the result of a focussed literature review of academic papers that discuss 'resilience' in social, ecological and socio-ecological systems. As such it analyses these existing conceptions to distil these diverse views into a set of key characteristics that might help clarify the value of resilience to engaging with development challenges in a changing climate.

\subsection{The resilience concept across disciplines}

'The term resilience is encountered in many disciplines, but no definition is common to all. Different elements or attributes of resilience are emphasized, but all definitions speak in a general way to the continued ability of a person, group, or system to adapt to stress - such, as any sort of disturbance-so that it may continue to function, or quickly recover its ability o function, during and after stress, (CPPSC 2011: 13)'

In the field of Psychology, ' ...resilience is defined as the quality that prevents individuals who are at genetic risk for maladaptation and psychopathology from being affected by these problems' (Chicchetti et al., 2004: 17325). The field of structural and engineering science has also explored and employed resilience. For example, the concept of seismic resilience of buildings understands it to be the property of a system which has: '1. Reduced failure probabilities; 2. Reduced consequences from failures, in terms of lives lost, damage, and negative economic and social consequences; 3. Reduced time to recovery' (Bruneau and Reinhorn, 2006: 1). This has underpinned ideas around climate resilient design that dominate adaptation discussions related to infrastructure (McDaniels et al., 2008).

Economic theory has incorporated resilience thinking in terms of the internal motivation and stimulus of private or public policy that enables a system to recover from a severe shock (Rose, 2004). Economic resilience has been applied at micro level (individual behaviour of firms, households or organisations), meso level (economic sectors, individual markets, cooperative groups, or cities), and macroeconomic (all individual units and markets combined) (ibid). At county level, this has been particularly significant in small island economies in relation to economic openness and natural hazard-induced disaster events, as well as to regional and urban development elsewhere (Briguglio et al, 2009). Business management approaches have also drawn on resilience as a strategy to manage disaster impacts, including from property damage to stocks and indirect business interruption to flows (Webb et al, 2000).

Moser (2008:5) reviews understandings of resilience in the social sciences to argue that most theories in this domain are "...derivative of the ecological theories from which resilience first emerged." There is widespread consensus amongst social and natural scientists that studying resilience involves the adoption of cross-disciplinary and multidisciplinary methods, as natural and social systems are highly integrated (Folke, 2006). While a high degree of interconnectedness between social and ecological systems is widely acknowledged, theories have emerged that are based variously on an understanding of resilience in social systems (or social resilience), those that stress resilience in ecological systems, and those that see the two as highly interconnected. 
The Socio-ecological System (SES) has emerged as a conceptual entity that can give the social and ecological systems the same weight in their analysis (Folke, 2006). These are '... linked systems of people and nature. The term emphasises that humans must be seen as a part of, not apart from, nature - that the delineation between social and ecological systems is artificial and arbitrary' (Simon, 2009). Mayunga (2007) acknowledges the interconnection of human and ecological systems by stating that both natural capital (air, soil, etc.) and social capital (trust, norms and networks) have a role in determining the resilience of a system. This is in contrast to Folke (2006), who does not isolate human/social and natural/ecological factors, seeing them instead as a highly integrated, systemic 'whole'. Central to resilience thinking in socio-ecological systems is the adaptive cycle through which all systems go through four phases - 'exploitation, conservation, release and renewal' (Gunderson and Holling 2001: 5). Closely associated with this is the notion of Panarchy that explains how adaptive cycles are simultaneously taking place within system components at different scales (ibid).

\subsection{Aims and Methodology}

This review aims to distil a set of characteristics of resilient systems based on an analytical review of resilience-related literature. Given the cross-cutting and cross-sectoral nature of climate change vulnerability, impacts and adaptation, the literature reviewed is necessarily limited. It focuses particularly on literature from social science-ecology interface, and aims to capture the breadth of literature in particular related to society, ecology and socio-ecological systems. This is because first, a substantial number of theorists (cited through the sections to follow) who discuss resilience as a way of engaging with climate change impacts (the primary purpose of this paper) operate in these contexts. Second, within the social sciences (the epistemological context of this paper) most discussions on resilience have been routed in social and ecological systems and have moved towards operating in the context of the coupled socio-ecological systems (SES) (Moser 2008). Third, a vast majority of the world population across rural, urban and peri-urban areas most vulnerable to climate change impacts and disasters, directly relies on ecological services for livelihoods and wellbeing (through, for instance, a reliance on agriculture) (ISET 2008). Engaging with the social and ecological dimensions and the nature of their interaction therefore provides a central axis for analysing 'resilience' in the context of climate change. Through the discussion in section 1.2, the authors acknowledge that a number of disciplines explore the concept of resilience but this review limits itself to papers that largely focus on social, ecological and socio-ecological systems.

The methodology undertaken was based on a 'systematic review process' (Gasten 2010). First, a relevant objective for the review was developed through wide consultation with colleagues engaged in research on climate change, disasters and resilience (the intended users of this article). Second, key search terms (e.g. 'resilience', 'climate change resilience', 'social resilience', 'disaster resilience', 'socio-ecological systems') were consistently applied in academic journal databases/Indexes (e.g. JSTOR, GreenFILE, Web of Science) to ensure a comprehensive pool of literature was obtained. Third, once this initial pool was secured, exponential discriminative snowball sampling was employed to help refine resources being collected (Denzin 2005). Exclusion criterion were developed and papers focussing on resilience in the context of society, ecology, SESs, climate change and disasters were included due to the reasons mentioned earlier.

A criterion for analysis was developed to review each paper in a systematic manner. The criteria focused on garnering the definition of resilience employed or developed by the paper 
under review, its characteristics, components and any discussion on the interplay of resilience with concepts of vulnerability ${ }^{3}$ and adaptive capacity ${ }^{4}$. From this analysis a set of ten characteristics common to many papers was distilled. In addition to academic journals, we also reviewed contemporary discussions on resilience through key word internet searches in order to capture the use of resilience for research programmes or development interventions.

Like all reviews, this one has its limitations. First, resilience is a burgeoning field of academic inquiry and so it is possible that some influential papers published after the review took place have not been included. Second, despite the use of a systematic review methodology, the synthesis of key characteristics to some extent reflects the subjective appraisal of the authors. Third, although it provides an improved academic foundation for adaptation practice based on resilience thinking, the review does not provide explicit policy prescriptions or recommendations

\section{Characteristics of Resilience}

This review article provides a guide to common and overlapping characteristics of resilience. The results suggest the range of dimensions that practitioners engaging with climate impacts can learn from the resilience concept, tailoring characteristics most relevant to their work. The following sections outline these characteristics, along with analytical commentary on their salience for wider adaptation contexts.

\subsection{High diversity}

Diversity is frequently cited in the literature as fundamental to resilience (Folke 2006; Holling, 1973; Resilience Alliance, 2009; Carpenter et al., 2001). Klein et. al. (2003: 39) underline the recurring theme of diversity within the body of thought on ecological resilience to note that '...many ecologists argue that resilience is the key to sustainable ecosystem management and that diversity enhances resilience, stability, and ecosystem functioning,'. Holling (1973) was one of the first to argue that high diversity in the range of functional groups within a system is seen to contribute greatly to its resilience. This underlines the importance of nurturing ecological diversity but also stresses the need for a range of available economic opportunities, a diversity of partnerships, and 'the significance of bringing additional constituencies into the policy arena' (Berkes, 2007: 289).

Different forms of diversity are interrelated. For instance, 'rural livelihoods and well-being are strongly dependent on the diversity and health of ecosystems and the services they provide,' (ibid: 289). Cutter et. al. (2010) point out that single sector economies are less resilient and more prone to being affected by extreme events. Adger (2000) emphasises the importance of communities relying on diverse natural resources as it insulates them from the 'boom and bust nature of markets', environmental variability and extreme weather events, which may adversely impact some resources. This point is also elucidated by Norris et. al. (2008: 134) who note 'Communities that are dependent on a narrow range of resources are less able to cope with change that involves the depletion of that resource.' Diversity may also be reflected in the variety of stakeholders engaged in an adaptive process, for instance, Osbahr (2007) demonstrates the importance of stakeholder diversity to the continued operation and success of an agriculture-horticulture project. The Rockefeller Foundation (2009: 2) highlights a diversity of planning, response and recovery activities as an essential component of resilience to climate change because 'a diversity of options has greater potential to match the particular scenario of impacts that occur'.

The diversity characteristic can be used to critique adaptation approaches that focus on linear and often technology-led solutions, such as new seed varieties or increasing the tolerance of bridges (McGray et. al., 2007). Emphasis on diversity in the resilience literature 
would suggest instead that adaptation approaches expand the range of different future scenarios for which a system is equipped, such as: thinking beyond only new seed varieties and to consider other important technologies; the development of non-farm livelihood opportunities; or on building contingencies for alternate routes in case bridges fail (Berkes, 2007). Despite this attention, there is much less attention in the literature to issues of power and politics associated with the inclusion of a diversity of voices (see section 3 ).

\subsection{Effective governance and institutions}

A number of different approaches stress the value of effective governance and institutions in building systems resilience. Mayunga (2007) stresses the importance of trust, norms and networks within a system, perhaps manifested through a large number of credible civil society institutions such as religious organisations and recreational clubs. Adger (2000: 351) examines how institutions must be seen as legitimate which in turn is a product of the level of 'inclusivity or exclusivity, and hence how effective they are in oiling the wheels of society'.

A key theme running through resilience thinking is the need for decentralised organisational structures and policies ${ }^{5}$. These are regarded as more flexible to cope with change and more in touch with the needs of communities and local realities (Folke, 2006; Rockefeller Foundation, 2009; Ostrom, 2009; Dovers and Handmer, 1992; Osbahr, 2007). Osbahr (2007: 14) notes that 'governance, the structures and processes by which societies share power, shapes individual and collective actions and can be formally institutionalised'. There is therefore a need for 'polycentric and multi-layered institutions to improve the fit between knowledge, action and the context in which societies can respond more adaptively at appropriate scales' (ibid: 14). Carpenter et. al. (2001: 778) underline the importance of institutions that can facilitate learning and 'experiment in safe ways, monitor results, update assessments, and modify policy as new knowledge is gained'.

The implication is the need to consider institutions and government structures as more than conduits or partners in the delivery of services supporting adaptation. Working with government institutions on devolution/decentralising processes and enhancing accountability could yield positive, robust, long- term results. This is in spite of the fact that such actions may not be sharply focussed on achieving adaptation outcomes or on specific climate impacts.

At the same time, simply building a greater number of institutional and governance structures will not necessarily create resilient systems. Institutions operate in the context of complex webs of power relations and are structures through which the powerful exercise their authority in social systems (Kenneth, 2005). Governance structures (both formal and 'informal') need to be understood in order to make informed decisions and recognise that resilience building activities will cause shifting power dynamics and trade-offs (Leach 2008). Institutional structures therefore need to be tailored to the setting in which they operate in order to work towards more equitable governance (see section 2.7) arrangements and diversity.

\subsection{Acceptance of uncertainty and change}

Resilience thinking is closely associated with the ability of systems to deal with uncertainty and change (Folke 2006). Underlining this characteristic of resilience, Norris et. al. (2008:130) note that 'stability' or the failure to change could be a way of determining the lack of resilience:

'The resilience of systems, for example, depends upon one component of the system being able to change or adapt in response to changes in other components; and thus the system would fail to function if that component remained stable, (ibid: 130).' 
The Asian Cities Climate Change Resilience Network (ACCRN), stresses the need for 'flexibility at an individual, organizational, and systemic level, with each level able to respond and contribute to each situation, and to respond to shifting and unpredictable circumstances' (Rockefeller Foundation, 2009: 2). This may be manifested, for example, as decentralised decision-making systems within organisations that have a role in determining the resilience of systems.

In contrast, many adaptation projects and policies may be formulated with an assumption that they will progress logically, in a linear fashion. This may be led by a technologically driven approach, but also because systems of project funding, management, monitoring and evaluation take a more linear approach and do not incentivise strategies for dealing with the high degree of uncertainty that exists in socio-ecological systems. Some of the other characteristics discussed in this review offer some insight on how to accept and engage with uncertainty, including flexibility, redundancy and effective institutional structures.

While this strain of analysis has contributed to a proliferation of debates on the development of systems that engage and accept change, there remains a need to translate this idea that originated in the ecological sciences into settings with complex social dimensions (Cannon and Mueller-Mahn 2010). Even though experiments in adaptive policy making, adaptive management and adaptive governance of socio-ecological systems are all working towards this end, this remains an emerging field of knowledge.

\subsection{Non-equilibrium system dynamics}

A non-equilibrium approach argues that restoring equilibrium may return a system to a state where it is vulnerable to the impact of the same perturbation again. Holling (1973: 2) engaged with this characteristic in his analysis of the resilience of ecosystems, arguing that,

'....an equilibrium centred view is essentially static and provides little insight into the transient behaviour of systems that are not near the equilibrium. Natural, undisturbed systems are likely to be continually in a transient state'.

While inherently linked to accepting 'uncertainty and change' (section 2.3), this characteristic adds another element. This demonstrates that rather than working towards making systems return to stable states after a disturbance, there needs to be a recognition that there are sets of relationships amongst a number of different system elements and each is organised around individual equilibriums (ibid). A disturbance may change the position of these components within a system, but the system will persist as long as the relationships between these components remain similar (ibid). This persistence of relationships then becomes a measure of the system's resilience. Folke (2006: 253) also refers to this characteristic when he writes,

'Old dominant perspectives have implicitly assumed a stable and infinitely resilient environment where resource flows could be controlled and nature would self-repair into equilibrium... The resilience perspective shifts policies from those that aspire to control change in systems assumed to be stable, to managing the capacity of socialecological systems to cope with, adapt to, and shape change.'

Similarly, an analysis of resilience in a part of the Dutch coast constructed a picture of a coast that is

...continuously changing, so no original or equilibrium state can be identified. Moreover, perturbations are not isolated events from which a coastal system may or may not recover, but are ever-present and occur at different temporal and spatial scales, (Klein et. al 2003: 39) .

Despite the dynamic nature of the adaptation issue, summarised as the problem of hitting a moving and uncertain target, adaptation projects often fail to acknowledge the dynamism that 
exists in real situations, instead attempting to 'control' environments. For example, many adaptation interventions that focus on ensuring that infrastructure is able to function despite the exigencies of a changing climate stem from a discourse that attempts to accurately model the nature of changes to come and develop plans based on scenarios (Hallegatte 2009). In this case, resilience thinking would urge adaptation planners and practitioners to look beyond only forming plans based on predicted changes to the climate but as discussed earlier in this paper, also consider failure scenarios and redundancy (Wilby and Dessai, 2010). For adaptation responses based on social and human systems this means acknowledging that societies/communities are constantly in flux and the intention should not be to 'preserve' or ensure status quo but to effectively empower individuals and institutions to deal with a variety of changes and disturbances that will occur (Pelling, 2010).

However, it is also important to note that Holling (1973) and others base their theories on ecological systems, using them as an analogy for systems with social components. While the conceptual contribution of this strain of thinking is clear, certain key elements need further exploration. For example, explaining relationships in a purely ecological system (e.g. food chains) is perhaps far less problematic than understanding social relationships that could have a higher degree of dynamism and arbitrary interactions.

\subsection{Community involvement and inclusion of local knowledge}

Community engagement, ownership, participation and indigenous/local knowledge are frequently stressed in the reviewed literature (Manyena, 2006; Mayunga, 2007; Ostrom, 2009; Nelson et al., 2007; Dovers and Handmer, 1992; Berkes, 2007; Osbahr, 2007, Norris et. al. 2008, CDRSS 2006). Manyena (2006: 438) critiques the United Kingdom's Resilience Programme and finds that while 'it will improve the coordinated response capabilities of emergency services and other government agencies,' it fails to involve the community. These, he argues, are the group who will inevitably have to combat emergency situations if the scale of disturbance overwhelms the official response capacity. This is also reflected in the National Research Council report by the Committee on Private-Public Sector Collaboration to Enhance Community Disaster Resilience (2011:5) that stresses the importance of representatives of the 'full fabric' of the community being represented in decisions related to the disaster cycle is considered critical to the development of community resilience. Similarly Norris et. al. (2008: 143) speaking in the context of building community resilience to disasters, extend this argument by adding, '...community members must assess and address their own vulnerabilities to hazards, identify and invest in their own networks of assistance and information;' they claim that while individuals from outside local communities can help build an enabling environment to foster recovery, communities must be empowered to 'take charge of the direction of change'. The Committee of Disaster Research in the Social Sciences notes (2006: 237) 'engagement' as one four core principles of building resilience to disasters, they believe that,

'Development actions that address disaster reduction (and other significant issues) must be formulated through a fair and equitable process that provides an opportunity for all affected parties to participate.'

Ostrom (2009:438) advocates greater ownership of natural resources within the system by its users arguing that when users have 'full autonomy at the collective-choice level to craft and enforce some of their own rules, they face lower transaction costs as well as lower costs in defending a resource against invasion by others'. This notion of co-management or greater ownership of resources by communities is raised by Nelson et. al. (2007: 409) who argue that the strong normative message from resilience research is that shared rights and responsibility for resource management (often known as co-management) and 
decentralisation are best suited to promoting resilience'. Berkes (2007) highlights the use of different forms of knowledge as one of four key areas of resilience in the context of climate change, and says that community-based monitoring and indigenous observations are significant in this regard because they fill in the gaps of global science and provide insights regarding local impacts and adaptations.

Researchers highlight community involvement as an important characteristic of resilience but there is little discussion in the reviewed literature of the political economy constraints to community resilience. There is scant acknowledgement of power structures that prevent the stewardship of natural resources by communities, the inclusion of local knowledge and community ownership/co-management of natural resources. Community involvement and local knowledge have been at the forefront of community based adaptation approaches, but tend to work within existing systems of governance to deliver project objectives rather than challenging them (Reid et al., 2009).

There is also little analysis of the dominant discourses of knowledge that privilege canonised, institutional or 'scientific' information over that which may be gained through more egalitarian and participatory approaches. At the same time, in the context of climate change adaptation, there also needs to be an acknowledgement of the limits of community knowledge and consequently, the need for approaches that combine the best of scientific knowledge with information from those on the frontlines of the battle against climate change (Sillitoe, 2007).

\subsection{Preparedness, planning and}

Preparing and planning for disturbances also characterises resilient systems. Cutter et. al. (2008: 4) speaking of hazard mitigation note, "Federal, state, and local governments throughout the United States are slowly coming to realize that planning is an important tool for increasing resilience." Planning requires relevant and timely information, as well as embedding disaster preparedness plans within existing institutional processes, such as district and local development plans. Another aspect of preparedness is redundancy (Bruneau 2003). This is when 'processes, capacities, and response pathways within an institution, community, or system allow for partial failure within a system or institution without complete collapse' (Rockefeller Foundation, 2009: 2). Norris et. al. (2008: 134) too discuss redundancy as a key property of resilience and understand it to be 'the extent to which elements are substitutable in the event of disruption or degradation.' Secondly this approach underlines the necessity of 'planning for failure', 'so that break-downs happen gracefully, not catastrophically - for example, when flood gates break, they do so in a way that channels floodwaters to uninhabited flood zones' (Rockefeller Foundation, 2009:2). Planning for failure can be operationalised by decentralised organisational structures, so that the failure of the central authority does not lead to system collapse, and through the explicit inclusion of system failure scenarios in any response plans.

Given the uncertainty inherent in modelling and projecting future climate impacts, climate change adaptation interventions must be prepared for a wide range of future possibilities. Nevertheless, building in redundant capacity will require the devotion of proportionately increased resources which may be unrealistic in many parts of the world that are struggling to provide a basic capacity to tackle existing climate shocks and stresses. Also, it may be harder to develop system failure scenarios for social systems than for physical infrastructure as it is impossible to accurately predict patterns of social behaviour in times of crises. However, building in capacity and redundancy is increasingly gaining attention through the notion of adaptive capacity. By shifting focus of development interventions from 'supplying' development projects to facilitating adaptive capacity of individuals, communities and 
processes, there is an investment in agency for preparedness, planning and readiness (Ensor, 2011; Levine et al., 2012).

\subsection{High degree of equity}

A number of theorists engage with the idea that a high degree of equity in a system leads to its increased resilience (Adger et. al., 2002: Nelson et. al,. 2007; Adger, 2000; Twigg, 2007, CDRSS 2006). Equity considerations relate to any changes to the resilience of human systems as these will involve changes in the distribution of impacts from disturbances. Equally, systems may become less resilient where issues of justice and equity are not taken into account (Nelson et al., 2007). Cutter et. al. (2010) examine the resilience of regions in 8 states of the U.S. to argue that regions with higher equity are likely to be more resilient.

Twigg (2007) specifies the equitable distribution of wealth and assets and an equitable economy as essential to building community resilience. Adger links stable livelihoods with sustained economic growth, itself promoted over the long term by the 'equitable distribution of assets within populations', linking this to both enhancement of aggregate demand within the economy and workforce productivity (2000: 355). The Committee on Disaster Research in the Social Sciences of the National Research Council (CDRSS 2006: 222), binds the notion of resilience to the idea of sustainable development and equity to argue that to increase resilience there is a need to '... improve equity within generations by providing for sufficient low-cost, low-risk development opportunities for the least advantaged.'

Adaptation responses can be differentiated by those that consider vulnerability to climate change as a property that resides within the system and those that consider vulnerability to result from factors that are external to it (O'Brien et al., 2007). The latter are often associated with 'hard' interventions such as building breakwaters and 'climate proofing' roads to withstand climate extremes. These structural approaches, in developing technical solutions may fail to adequately acknowledge the importance of issues of equity which may require attention to 'soft' internal social systems such as learning and knowledge management, or issues of class, gender, voice and accountability. Brown (2011: 29) links adaptation, equity and resilience when she posits that for adaptation to be sustainable, it must engage with '...multi-dimensional poverty reduction and the need for fundamental institutional reconfiguration in support of long-term equity and resilience.'

\subsection{Social capital, values and structures}

Social capital, built on trust, norms and networks is cited as an important element for building resilient systems (Mayunga, 2007). Robust civil society institutions are viewed as able to foster cooperation and coordination in a community, this in turn can lead to a greater amount of trust and respect amongst its members and more equitable access to resources and greater resilience (ibid). Norris et. al. (2008) count social capital (which is a combination of social support, social embeddedness, organisational linkages, leadership, sense of community and attachment to a place) as one set of resources that generate community resilience. The Committee on Disaster Research in the Social Sciences of the National Research Council (2006) mentions social capital as a key element of a community's resilience to disasters and argue that social capital fosters social networks that create interpersonal trust. This in turn, allows the community to solve problems effectively, build consensus and reduce conflict (ibid). Cutter et al. (2010:9) too discuss the importance of social capital to resilience and interpret this as '....sense of community, place attachment, and citizen participation.' Ostrom (2009) discusses the capability of system users to organise for better ecosystem management, arguing that a high degree of trust and shared ethical standards makes it easier to reach agreements and also reduces the need to carefully 
monitor resource use by different users. Twigg (2007) also says that shared community values are a characteristic of disaster-resilient communities.

While there have been important advances in community based adaptation approaches in recent years, many 'project' based adaptation interventions are unable to accommodate the complexity of working to explicitly foster community networks and address multiple values and interests due to the double constraints of time and resources. This characteristic of resilience thinking would foreground activities to mediate differences, develop trust and build on shared social values within communities, whilst recognising that some adaptation activities themselves may erode community trust, institutions and shared values and therefore prove maladaptive.

However, these social structures may not always act to enhance resilience and may in fact lead to conflict in relation to climate change adaptation (O'Brien, 2009). Mayunga's (2007) relatively uncritical faith that civil society organisations will foster cooperation in a community ignores the possible variety of values, agendas, interests that privilege a certain section of the 'community' over another. Also, despite a well-developed critique in the development literature, climate change writers pay little attention to the inherent heterogeneity of communities and the high degree of variety in their internal dynamics (Anderson, 1983). Finally, Moser (2008) discussed the importance of 'social capital' to resilience but highlights the need to acknowledge inherent problems such as trade-offs between groups at the local level and review the notion of the 'community' as a cohesive entity.

\subsection{Learning}

A number of theorists reviewed here highlight the need for iterative program processes and organisational learning to promote resilience. Learning is also central to the notion of adaptive management (Gunderson and Holling, 2001). This considers a range of plausible hypotheses about future changes in the system, weighs a range of possible strategies against this wide set of potential futures, and then favours actions that are robust in the face of uncertainties (Wilby and Desai, 2010). Moser (2008: 17) underlines the inherent importance of learning to the idea of resilience to note,

'...resilience means more than just responding to, and bouncing back after, an extreme event. It also involves the capacity to change and adapt to changing environmental conditions, and that, in turn, requires the essential abilities to cooperate, learn, and apply the lessons toward continued resilience under future conditions.'

O'Brien and O'Keefe (2010:378) note that: '...learning can enhance the capacity to prepare an effective response to disastrous situations.' They go onto argue that organisations engaged in dealing with disasters need to understand the vital importance of double loop learning and intrinsically link learning and resilience to claim that '... resilience building is a learning process at all levels. Institutional learning empowers at the local level and strengthens governance,' (ibid:381). A good example of how learning can be built into programmes aimed at building resilience and adaptive capacity are Shared Learning Dialogue methods that involve

'... multiple opportunities to share, generate, and understand new knowledge. Multiple iterative sessions allow for sequential growth in understanding and typically lead to increased levels of comfort and more meaningful dialogue among participants' (ISET, 2010 :2).

While some pilot adaptation approaches are iterative in nature and embody the principles of adaptive management, many approaches still do not build in learning components from the start (Peterson et. al., 1997, Thornton and Singh, 2010). Most adaptation interventions have 
monitoring and evaluation (M\&E) components built in but in most cases this is a system to track progress. Resilience thinking would, for example, encourage active learning by urging adaptation planners to realise the full potential of $M \& E$ and take it from being a mere procedure of monitoring outputs to a system which engenders effective learning, change and possibly transformation for the better (Thornton and Singh, 2010).

In spite of these assertions, 'programme/project driven' approaches to adaptation (and increasingly to resilience) need to show impact in a limited period, usually from one to five years. In addition, limited experience and documented examples of adaptive management and learning approaches to tackling climate change may limit uptake of these approaches (Tanner et al. 2012).

\subsection{Adoption of a cross-scalar perspective}

At the heart of the resilience concept seems to be an acknowledgement of the high level of interconnectedness between the various components of a system (through constructs such as Panarchy). This in turn means that resilient systems have perspectives that transcend the specificities of the local and take a broader view of events. Holling (1973) compares the resilience of fish stocks in a closed, local ecosystem like that of a lake to that of pest populations which are highly dispersed in space and time to find that the latter are far more resilient. Nelson et. al. (2007) argue that networks which transcend scales are found to have greater resilience. Similarly, the Committee on Disaster Research in the Social Sciences of the National Research Council (2006) embodies this principal when it highlights the importance of 'vertical integration' of communities to their resilience to disasters. Vertical integration is described as 'structural and functional relations of [a community's] various social units to extra community systems," and is seen to be important for a number of reasons but also because it "helps to expand the resources (funds, expertise, influence, and so forth) potentially available to the community,' (ibid: 233).

Extending thinking on the importance of cross-scalar perspective could lead to, for example, an understanding of how an urban adaptation project to be successful has to take into account neighbouring rural areas as migration into the city, the supply of essential goods and services are all hinged on factors there. Taking another example, this would also mean that those designing programmes to respond to climate impacts may need to consider the establishment of networks across regions and, for instance, acknowledge the adaptive potential of planned migration (Adger et. al., 2002).

While promoting resilience one needs to be alive to the importance of working across scale, it is important to be cognizant of the fact that a number of theorists highlight the importance of connectedness across scales and the value of networks in building resilience but very few examine the nature and form that these networks should take. Social, political and economic ties across scales can be malignant (e.g. colonialism or neo colonialism) if adequate attention is not paid to issues of equity and justice.

\section{Conclusion}

Reviewing literature on the application of resilience thinking for climate change and development has yielded insights into the characteristics of resilient systems. However, a number of gaps in understanding remain.

Firstly, the relationship of resilience with concepts such as vulnerability and adaptive capacity remains poorly defined. Certain definitions overlap vulnerability with resilience, or even threat them as opposites, whereas others treat vulnerability as an entirely separate concept (Manyena, 2006). Conceptually, resilience can be differentiated as referring to state shifts 
between domains of attraction, or the ecological limits of how far a system can be disturbed without shifting to a new regime, while vulnerability refers to structural changes in the system, implying changes in its stability landscape (Gallopín, 2006; Logan, 2010). It is possible to see how some exposure to shocks and stresses would enhance the vulnerability of a system but could also provide the experience required for improved institutional memory in responding to future disturbances, thereby enhancing resilience (Moser, 2008). On the other hand, a high amount of repeated exposure could deplete resources within a system, increase vulnerability and deplete resilience.

A similar degree of confusion exists with the relationship between resilience and adaptive capacity (Klein et. al. 2003). One strand of academic opinion argues that adaptive capacity refers to the capability/ability/potential of systems or components within systems to be resilient to disturbances (Berkes, 2007; Osbahr, 2007). Another strand regards adaptive capacity as a reference to that component of resilience that relates to 'learning' by systems in response to disturbances (Resilience Alliance; Carpenter et al., 2001; Mayunga, 2007). .

Second, measuring resilience is still a topic of debate, with little agreement on systems of measurement and monitoring. While there is some clarity on the factors that cause vulnerability and enhance resilience, there is considerably less clarity on measurement (Cutter et. al. 2008). Twigg (2007) employs five thematic areas to organise indicators of disaster resilience at the community level, including governance; risk assessment; knowledge and education: risk management and vulnerability reduction; and disaster preparedness and response. Carpenter et. al. (2005: 941) acknowledge the difficulty of measuring resilience and suggest the use of surrogates (as opposed to indicators) because "...aspects of resilience in SES may not be directly observable, but must be inferred indirectly." Such aspects of resilience may be measured through stakeholder assessments, model explorations, historical profiling and case study comparisons.

One approach has been to develop a set of principles of measuring resilience rather than a universally applicable set of indicators, crucially including the need to specify "... what system state is being considered (resilience of what) and what perturbations are of interest (resilience to what)," (Carpenter et. al. 2001: 778). Bruneau et. al. (2003) propose a schema to quantify and measure resilience across four performance measures: technical, organisational, social and economic, and four performance criteria: robustness, redundancy, resourcefulness and rapidity. Similarly, Cutter et. al. (2010) argue that disaster resilience can be measured through the development of variables that gauge social, economic, institutional and infrastructural resilience, as well as community/social capital.

Despite this development in frameworks for measurement however, a range of authors have identified the significant lack of methodological development for measuring resilience (Cabell and Oelofse, 2012; Bennett et al. 2005, Carpenter et al. 2006, Fletcher et al. 2006 and Darnhofer et al. 2010).

Divergent viewpoints and weak methodologies on measurement have contributed to a lack of clarity on, and certainly a lack of consensus on, ways of operationalising resilience. One explanation is that resilience remains a conceptually strong but operationally weak precisely because the concept carries, '... .limited scope for measurement, testing, and formalisation' (Klein et. al. 2003: 41). Similarly, Carpenter et. al. (2005: 941) note that '... there is little experience with estimating the resilience of SES, and little understanding of the sensitivity of resilience measures to changes in SES.' Some authors hence underline the urgent need for 'demonstration projects' that provide a clearer picture of how resilience may be operationalized (Klein et. al. 2003; CDRSS, 2006). One way in which this problem manifests itself is that while each of the characteristics discussed here is valuable, there is yet no clarity on 'what combination' or 'how 
many' of such characteristics would make a system resilient. This is something which can only be gauged through field-testing or the collection of case studies.

Third, as highlighted in a number of sections above, in transplanting the resilience concept from ecological to complex socio-ecological settings, there is limited engagement with issues such as power, agency, politics and influence (Kuhlicke 2010, Swanstrom 2008, Leach, 2008). This becomes important, for example, when considering the nature of institutions as part of any resilience building initiative; in designing processes of community participation around adaptation interventions; in encouraging community ownership of natural resources; in fostering community bonds; or engendering cross-scalar linkages and networks. Unless critical issues of power are acknowledged and engaged with, the resilience concept will retain minimal validity for social systems. If it fails to do so, '...the resilience approach is in danger of a realignment towards interventions that subsumes politics and economics into a neutral realm of ecosystem management, and which depoliticises the causal processes inherent in putting people at risk' (Cannon and Mueller-Mahn, 2010: 13).

Finally, this paper aims to stimulate debate on the resilience characteristics presented and their usefulness in tackling climate change impacts in a development context. The authors urge theorists and practitioners to critically analyse these before tailoring them for their individual settings and circumstances. 


\section{References}

Adger, W.N. Kelly, P.M. Winkels, A. Huy L.Q. and Locke, C., 2002. Migration, Remittances, Livelihood Trajectories, and Social Resilience. Ambio 31.4 .

Adger, W.N., 2000. Social and Ecological Resilience: Are They Related? Progress in Human Geography 24.3: 347-64.

Anderson, B., 1983. Imagined Communities. Verso, United Kingdom.

Bennett, E. M., G. S., Cumming, and Peterson, G. D. 2005. A systems model approach to determining resilience surrogates for case studies. Ecosystems 8(8):945-957.

Berkes, F., 2007. Understanding Uncertainty and Reducing Vulnerability: Lessons from Resilience Thinking. Natural Hazards 41.2: 283-95.

Booz Allen Hamilton. Redefining the Corporate Agenda. www.boozallen.com/media/file/138022.pdf [accessed on 8th December 2009].

Briguglio, L., Cordina, G., and Farrugia, N., 2009. Economic vulnerability and resilience: concepts and measurements. Oxford Development Studies, Oxford, UK

Brown, K., 2011. Sustainable Adaptation: An oxymoron? Climate and Development 3, 21 31.

Bruneau, M. and Reinhorn, A., 2006. Overview of the Resilience Concept, proceedings of the 8th U.S. National Conference on Earthquake Engineering, USA, 18-22 April.

Bruneau, M. Chang, S. Eguchi, R. Lee, G. O'Rourke, T. Reinhorn, A. Shinozuka, M. Tierney, K. Wallace, W. and Winterfeldt, D., 2003. A Framework to Quantitatively Assessand Enhance the Seismic Resilience of Communities. Earthquake Spectra, Volume 19, No. 4, pages 733-752,

Cabell, J. F. and Oelofse, M., 2012. An indicator framework for assessing agroecosystem resilience. Ecology and Society 17(1): 18.

Cannon, T., Muller-Mahn, D., 2010 . Vulnerability, resilience and development discourses in context of climate change. Natural Hazards Volume: 55, Issue: 3.

Carpenter, S. R. Bennett, E. M. and Peterson. G. D., 2006. Scenarios for ecosystem services: an overview. Ecology and Society 11(1): 29. 
Carpenter, S. R., B. H. Walker, J. M. Anderies, and N. Abel. 2001. From metaphor to measurement: resilience of what to what? Ecosystems 4:765-781.

Carpenter, S. Westley, F. and Turner, M., 2005. Surrogates for Resilience of SocialEcological Systems. Ecosystems 8: 941-944

Carpenter, S., Walker, B., Anderies, J.M. and Abel, N., 2001. From Metaphor to Measurement: Resilience of What to What? Ecosystems 4: 765-81.

Cicchetti, D. and Blender, J.A., 2004. A Multiple-Levels-of-Analysis Approach to the Study of Developmental Processes in Maltreated Children. Proceedings of the National Academy of Sciences of the United States of America. Vol 101. no. 50 17325-17326.

CDRSS (Committee on Disaster Research in the Social Sciences), $2006 . \quad$ Facing Hazards and Disasters: Understanding Human Dimensions. National Research Council, USA.

Committee on Private-Public Sector Collaboration to Enhance Community (CPSSC), 2011. Building Community Disaster Resilience through Private-Public Collaboration. Geographical Science Committee, National Research Council, USA.

Cutter, S. Barnes, L. Berry, M. Burton, C. Evans, E, Tate, E. and Webb, J., 2008. Community and Regional Resilience: Perspectives From Hazards, Disasters, and Emergency Management. CARRI Research Report 1

Cutter, S.L. Barnes, L. Berry, M. Burton, C. Evans, E. Tate, E. and Webb, J., 2008. A Place-based Model for Understanding Community Resilience to Natural Disasters. Global Environmental Change 18: 598-606.

Darnhofer, I. Bellon, S. Dedieu, B. and Milestad. R., 2010. Adaptiveness to enhance the sustainability of farming systems: a review. Agronomy for Sustainable Development 30(3):545-555.

Denzin, N.K. and Licoln, Y.S. 2005. The Sage Handbook of Qualitative Research. Sage, UK.

Dovers, S.R. and Handmer, J.W.,1992. Uncertainty, Sustainability and Change. Global Environmental Change 2.4: 262-76.

Ecological Sociology. Theorizing the relationship between the natural and the social. http://ecologicalsociology.blogspot.co.uk/2012_04_01_archive.html (accessed on $11 / 7 / 2012)$ 
Ensor, J. (2011) Uncertain Futures: Adapting development for a changing climate, Practical Action Publishing, Rugby.

Fletcher, C. S., Miller, C. and Hilbert, D. W. 2006. Operationalizing resilience in Australian and New Zealand agroecosystems. In Proceedings of the 50th Annual Meeting of the ISSS, ISSS Papers.

Folke, C., 2006. Resilience: The Emergence of a Perspective for Social-Ecological Systems Analyses. Global Environmental Change 16: 253-67.

Gaasten, M., 2010. Systematic Reviews and Evidence-Informed Policy: Overview. DFID Research and Evidence Division, UK.

Gallopin, G., 2006. Linkages between Vulnerability, Resilience and Adaptive Capacity. Global Environmental Change 16.3.

Gunderson, L. and Holling, C.S., 2001. Panarchy: Understanding Transformations in Human and Natural Systems. Island Press, Washington D.C. , USA.

Hallegatte, S., 2009. Strategies to adapt to an uncertain climate change. Global Environmental Change 19 (2), 240-247.

Holling, C.S. 1973. Resilience and Stability of Ecological Systems. Annual Review of Ecology and Systematics 4: 1-23.

IPCC TAR, 2001. Climate Change 2001: Impacts, Adaptation and Vulnerability. IPCC Third Assessment Report, Cambridge University Press.

ISET, 2008. Re-imagining the Rural-Urban Continuum: Understanding the role ecosystem services play in the livelihoods of the poor in desakota regions undergoing rapid change. Institute for Social and Environmental Transition-Nepal (ISET-N), Kathmandu, Nepal.

ISET, 2010. The Shared Learning Dialogue: Building Stakeholder Capacity and Engagement for Resilience Action. Climate Resilience in Concept and Practice Working Paper Series, Boulder, Colorado, USA.

Kenneth, A., 2005. Explorations in Classical Sociological Theory. Pine Forge Press, California, USA.

Klein, R. Nicholls, R. and Thomalla, F., 2003. Resilience to natural hazards: How useful is this concept? Environmental Hazards 35-45 
Kuhlicke, C., 2010. Resilience: a capacity and a myth: findings from an in-depth case study in disaster management research. Natural Hazards

Leach, M. (ed.) 2008. Re-framing Resilience: a Symposium Report. STEPS Working Paper 13, Brighton, UK.

Levine, S., Ludi, E. and Jones, L., 2012. Rethinking Support for Adaptive Capacity to Climate Change: The Role of Development Interventions, A report for the Africa Climate Change Resilience Alliance (ACCRA). Overseas Development Institute, London, UK

Logan, J.A. Macfarlane, W. W. and Willcox, L., 2010. Whitebark pine vulnerability to climate-driven mountain pine beetle disturbance in the Greater Yellowstone Ecosystem. Ecological Applications, 20(4), pp. 895-902.

Manyena, S.B., 2006. The Concept of Resilience Revisited. Disasters 30.4: 433-50.

Mayunga, J.S., 2007. Understanding and Applying the Concept of Community Disaster Resilience: A Capital-Based Approach. Draft working paper prepared for the summer academy, Megacities as Hotspots of Risk: Social Vulnerability and Resilience Building, Munich, Germany, 22-28 July 2007.

McDaniels, T. Chang, S., Cole, D., Mikawoz, J., and Longstaff, H., 2008. Fostering resilience to extreme events within infrastructure systems: Characterizing decision contexts for mitigation and adaptation. Global Environmental Change, Volume 18, pp. 310-318.

McGray, H. Hammil, A. and Bradley, R., 2010. Weathering the Storm: Options for Framing Adaptation and Development. World Resources Institute, Washington DC, USA.

Moser, S., 2008. Resilience in the face of global environmental change. CARRI Research Report 2

Nelson, D.R. Adger, W.N. and Brown, K., 2007. Adaptation to Environmental Change: Contributions of a Resilience Framework. Annual Review of Environment and Resources 32: 395-419.

Norris, F. Stevens, S. Pfefferbaum, B. Wyche, K. and Pfefferbaum, R., 2008. Community Resilience as a Metaphor, Theory, Set of Capacities, and Strategy for Disaster Readiness. American Journal of Community Psychology 41:127-150

O'Brien, K., 2009. Do values subjectively define the limits to climate change adaptation? In: Adapting to Climate Change: Thresholds, Values, Governance [Adger, N., Lorenzoni, I. And K. O‘Brien (eds.)]. Cambridge: Cambridge University Press, pp. 164 - 180. 
O'Brien, G. and O'Keefe, P., 2010. Resilient responses to climate change and variability: a challenge for public policy. International Journal of Public Policy, Vol. 6, Nos. 3/4, pp.369-385.

O'Brien, K., Eriksen, S., Nygaard, L.P., Schjolden, A., 2007. Why different interpretations of vulnerability matter in climate change discourses. Climate Policy 7, 73-88.

Osbahr, H., 2007. Building Resilience: Adaptation Mechanisms and Mainstreaming for the Poor. Human Development Report Occasional Paper .

Ostrom, E., 2009. A General Framework for Analyzing Sustainability of Socio-Ecological Systems. Science 325: 419.

Pelling, M., 2010. Adaptation to climate change: from resilience to transformation. Routledge, Oxford,UK.

Peterson, G. Allesandro De Leo, G. Hellmann, J. Janssen, M. Kinzig, A. Malcom, J. O'Brien, K. Pope, S. Rothman, D. Shevliakova, E. and Tinch, R., 1997. Uncertainty, Climate Change, and Adaptive Management. Conservation Ecology 1(2): 4.

Reid, H., Alam, M., Berger, R., Cannon, T., Huq, S., and Milligan, A., 2009. Communitybased adaptation to climate change: an overview. PLA Notes No.60, pp.11-34.

Resilience Alliance. Resilience. www.resalliance.org/576.php [accessed on 7th July 2011].

Rockefeller Foundation, 2009. Building Climate Change Resilience. Rockefeller Foundation White Paper.

Rose, A., 2004. Defining and Measuring Economic Resilience to Disasters. Disaster Prevention and Management 13(4) pp307-314.

Swanstrom, T., 2008. Regional Resilience: A Critical Examination of the Ecological Framework. Institute of Urban and Regional Development, USA.

Sillitoe, P., 2007. Local Science v. Global Science: An Overview', in P. Sillitoe (ed.), Local Science vs Global Science: Approaches to Indigenous Knowledge in International Development. Bergahn Books, New York, USA.

Simon, S. H., 2009. Resilience Dictionary. Stockholm Resilience Centre. http://www.stockholmresilience.org/research/whatisresilience/resiliencedictionary.4.aeea4 6911a3127427980004355.html (Accessed on 7/3/2012) 
Tanner, T.M., Lockwood, M. and Seballos, F. (2012) Learning to Tackle Climate Change. IDS, Brighton.

Thornton, P. and Singh, S., 2002. Designing an M\&E Approach for Asian Cities Climate Change Resilience Network. The Second International Workshop on Mainstreaming Adaptation to Climate Change -Managing Adaptation Processes, 10-12 November 2010, New Delhi, India.

Twigg, J., 2007. Characteristics of a Disaster-resilient Community. DfID, London, UK.

Webb, G., Tierney, K. and Dahlhamer, J., 2000. Business and disasters: empirical patterns and unanswered questions. Natural Hazards Review, 1:83-90

Wilby, R.L. and Dessai, S., 2010. Robust Adaptation to Climate Change. Weather 65 (7), 180-185.

Wisner, B. Cannon, T Blakie, P. and Davis, I. 2004. At Risk: Natural hazards, people's vulnerability and disasters. Routledge, London, UK

\section{End Notes-}

1- This paper works with the following definition of climate change adaptation, is a process by which strategies to moderate, cope with and take advantage of the consequences of climatic events are enhanced, developed, and implemented.'(UNDP, 2005)

2- Disaster Risk Reduction is 'a systematic approach to identifying, assessing and reducing the risks of disaster. It aims to reduce socio-economic vulnerabilities to disaster as well as dealing with the environmental and other hazards that trigger them,' (Wisner B et al. 2004)

3-Definitions of vulnerability are vast as they are diverse, therefore unless otherwise specified, this paper works with the following definition of vulnerability, 'The degree to which a system is susceptible to, or unable to cope with, adverse effects of climate change, including climate variability and extremes. Vulnerability is a function of the character, magnitude, and rate of climate variation to which a system is exposed, its sensitivity, and its adaptive capacity.' (IPCC TAR, 2001)

4- This paper works with the following definition of adaptive capacity, "The ability of a system to adjust to climate change (including climate variability and extremes), to moderate potential damages, to take advantage of opportunities, or to cope with the consequences. "(IPCC TAR, 2001)

5- It would also be instructive to consider criticisms of this approach which argue that decentralisation in 'all' cases may not be the right solution; sometimes, a centralised system of control could perhaps be more effective in managing a number of processes in complex operational environments. 